\section{Epicuticular Wax Morphology and Composition are Related to Grapefruit Chilling Injury}

\author{
Roy E. McDonald, Harold E. Nordby, and T. Gregory McCollum \\ U.S. Department of Agriculture, Agricultural Research Service, U.S. \\ Horticultural Research Laboratory, 2120 Camden Road, Orlando, FL 32803
}

Additional index words. Citrus paradisi, postharvest, canopy position

\begin{abstract}
Differences in chilling injury (CI) susceptibility between 'Marsh' grapefruit (Citrus paradisi Macf.) from interior and exterior tree canopy positions were analyzed to investigate the hypothesis that epicuticular wax morphology and composition influence CI development during low-temperature storage. The sun-exposed surface of fruit from the exterior canopy had significantly more CI and larger wax platelets than the shaded surface of the same fruit. Interior canopy fruit had significantly less CI and smaller wax platelets than exterior canopy fruit. Hydrocarbons, primarily $n$ - alkanes, were significantly more abundant in the epicuticular wax on the surfaces of sun-exposed and exterior fruit compared with surfaces of shaded and interior fruit, respectively. Results of this study suggest that epicuticular wax plays a role in the development of external CI symptoms on grapefruit.
\end{abstract}

Grapefruit, like many other tropical and subtropical fruit, develop chilling injury (CI) when stored at temperatures below 10 to $12 \mathrm{C}$. Conditions and treatments that reduce weight loss (e.g., highrelative humidity, waxing) will reduce CI incidence (Wang, 1990).

Citrus and other fruit are covered with several layers of hydrophobic material, the outermost being epicuticular wax. Epicuticular waxes have increased cuticular resistance and reduced transpiration rates (Bain and McBean, 1967; Possingham et al., 1967) and reduced postharvest weight loss in 'Valencia' oranges [Citrus sinensis (L.) Osbeck] (Albrigo, 1972a). Additionally, Albrigo (1972a, 1972b, 1972c) related morphology and quantitative epicuticular wax changes to rind disorders and fruit quality deterioration in 'Valencia' oranges.

The chemical composition of citrus fruit epicuticular wax has been determined in several studies (Baker and Procopiou, 1975; Baker et al., 1975; El-Otmani and Coggins, 1985; Freeman et al., 1979). The major components of this wax are aldehydes, hydrocarbons, fatty acids, and primary alcohols. Nordby and McDonald (1990, 1991) related increased squalene, $\mathrm{C}_{23}$ to $\mathrm{C}_{25} n$ - alkanes, and $\mathrm{C}_{28}$ to $\mathrm{C}_{34} n$ -

Received for publication 20 July 1992. Accepted for publication 7 Jan. 1993. We thank Roxanne Wiseman, U.S. Dept. of Agriculture (USDA), and Ron Brlansky and Diann Achor, Citrus Research and Education Center, Lake Alfred, Fla., for technical assistance with scanning electronmicroscopy during the course of this work. Mention of a trademark, warranty, proprietary product, or vendor does not constitute a guarantee by the USDA and does not imply its approval to the exclusion of other products or vendors that also may be suitable. The cost of publishing this paper was defrayed in part by the payment of page charges. Under postal regulations, this paper therefore must be hereby marked advertisement solely to indicate this fact.

For wax morphology studies, additional fruit were obtained and hand-washed with tap interior and exterior tree canopy positions. water. Preliminary studies showed that gentle hand-washing did not disturb the epicuticular wax but removed foreign material that obstructed our view of fruit surfaces. Three samples of the fruit flavedo $(\approx 0.25 \mathrm{~mm}$ thick$)$ from each of five fruit from different trees and each canopy position and orientation were removed using a razor blade. A 5-mm cork borer was used to excise discs, which were attached to aluminum mounts with doublesided adhesive tape, frozen in liquid $\mathrm{N}_{2}$, and freeze-dried. Peel disks were isolated from fruit before and after 5 weeks of storage at $5 \mathrm{C}$, sputter-coated with 80 gold : 20 palladium, and examined with a Hitachi (Hitachi, Ibaraki, Japan) S-530 scanning electron microscope.

After harvest, epicuticular wax was isolated from each of five fruit from interior and exterior canopy positions. Individual fruit were placed in a porcelain crucible and swirled in $100 \mathrm{ml}$ chloroform for $2 \mathrm{~min}$. Each fruit then was rinsed with $25 \mathrm{ml}$ chloroform, and the combined extracts were reduced to near dryness on a rotary evaporator at 30C under reduced pressure. Sun-exposed and shaded surfaces of five fruit were bathed separately in chloroform to isolate their wax. Cholestane $\left(\mathrm{C}_{27} \mathrm{H}_{48}\right)$ was added as an internal standard, and the extracts were made up to $5 \mathrm{ml}$ with chloroform. A $1.0 \mu \mathrm{l}$ aliquot was injected into a gasliquid chromatograph on a $0.75 \mathrm{~mm} \times 30 \mathrm{~m} \times$ $1 \mu \mathrm{m}$ Supelcowax SPB-1 column (Supelco, Bellefonte, $\mathrm{Pa}$.) to separate the wax components. Thirty-four wax components were quantified by the internal standard. These components had been identified previously by Nordby and McDonald (1991) as belonging to four lipid classes: hydrocarbons, n-alcohols, $n$ - aldehydes, and terpenoids (compounds derived from isoprenes). The oven temperature was kept at $250 \mathrm{C}$ for $8 \mathrm{~min}$, increased $2 \mathrm{C} / \mathrm{min}$ to 265C, and kept there for $30 \mathrm{~min}$. Injection port and flame ionization detector temperatures were $300 \mathrm{C}$, and the carrier gas (helium) flow rate was $18 \mathrm{ml} \cdot \mathrm{min}^{-1}$. Major wax components are expressed as weight percentage of total All data were analyzed as a completely randomized design using SAS's analysis of variance procedure (SAS Institute, 1988).

Interior canopy fruit had significantly less CI than exterior canopy fruit (Table 1). Similarly, shaded surfaces of fruit from the exterior canopy had significantly less CI than sunexposed surfaces; this result confined the findings of Purvis (1980). Rindstaining, an important peel disorder of California 'Valencia' oranges, was more severe on exposed surfaces (El-Otmani et al., 1989).

Table 1. Chilling injury (CI) index and epicuticular wax composition of 'Marsh' grapefruit harvested from

\begin{tabular}{lccccc}
\hline \hline & & \multicolumn{4}{c}{$\begin{array}{c}\text { Wax components } \\
\text { (\% of total wax) }\end{array}$} \\
\cline { 3 - 6 } Fruit location & index & Hydrocarbons & Aldehydes & Alcohols & Terpenoids \\
\hline Interior canopy & 1.3 & 3.8 & 39.2 & 2.2 & 54.8 \\
Exterior canopy & 4.0 & 6.2 & 42.9 & 2.0 & 48.8 \\
Significance & $* * *$ & $*$ & $\mathrm{NS}$ & $\mathrm{NS}$ & $\mathrm{NS}$ \\
Sun-exposed & 6.6 & 18.2 & 34.7 & 3.2 & 43.9 \\
Shaded & 1.4 & 9.7 & 38.7 & 2.9 & 48.8 \\
Significance & $* *$ & $*$ & $\mathrm{NS}$ & $\mathrm{NS}$ & $\mathrm{NS}$ \\
\hline
\end{tabular}


Average wax platelet size on the peel of interior canopy fruit (Fig. 1A) and on the shaded portion of exterior fruit ( Fig. 1B) were similar-and smaller than on the sun-exposed portion of exterior fruit (Fig. 1C). Platelet size and shape did not change during 5 weeks of storage at 5C. Thus, larger platelet size was associated with greater CI development. However, with rindstaining, El-Otmani et al. (1989) reported that the sun-exposed side of fruit with no blemish had "crusty" plates, the fruit side with moderate rindstaining had fewer plates and a more amorphous wax structure, and fruit with severe rindstaining had no plates and amorphous wax.

The total mass of wax extracted was not related statistically to canopy position; however, wax composition varied with canopy position and orientation. Components of the epicuticular wax, in decreasing order of abundance, were terpenoids, aldehydes, hydrocarbons, and alcohols. Hydrocarbons, primarily $n$ - alkanes, were significantly less abundant in the epicuticular wax on shaded and interior fruit surfaces than on sun-exposed and exterior fruit surfaces, respectively (Table 1 ). The $n$ - alkane fraction also was higher in the epicutitular wax from sun-exposed than from shaded 'Valencia' oranges (El-Otmani et al., 1987). El-Otmani et al. (1987) suggested that fruit maturation and senescence are accompanied by relative and absolute increases in epicuticular wax $n$ - alkanes.

In previous work, we observed that squalene was present in trace amounts in the epicuticular wax of freshly harvested fruit or in fruit stored at 5C (Nordby and McDonald, 1990, 1991). Large squalene increases were found only after temperature conditioning at $15 \mathrm{C}$. In this study, we found squalene in trace amounts in interior and exterior canopy fruit; there were no relative differences between canopy positions.

The data from this study indicate that the morphology and composition of crystalline wax are influenced strongly by canopy position. The exposed side of a grapefruit reaches higher temperatures when exposed to sunlight than does the shaded side (Syvertsen and Albrigo, 1980). El-Otmani et al. (1989) suggested that the rind of the more-exposed side of fruit ages more rapidly than rind on the shaded side of the same fruit, and that fruit exhibiting rindstaining display more advanced senescence. Hence, the greater susceptibility of the exposed side to CI may be the consequence of accelerated senescence.

The results of this study also indicate that there is an optimal wax component ratio that confers greater CI tolerance. Present and pre-

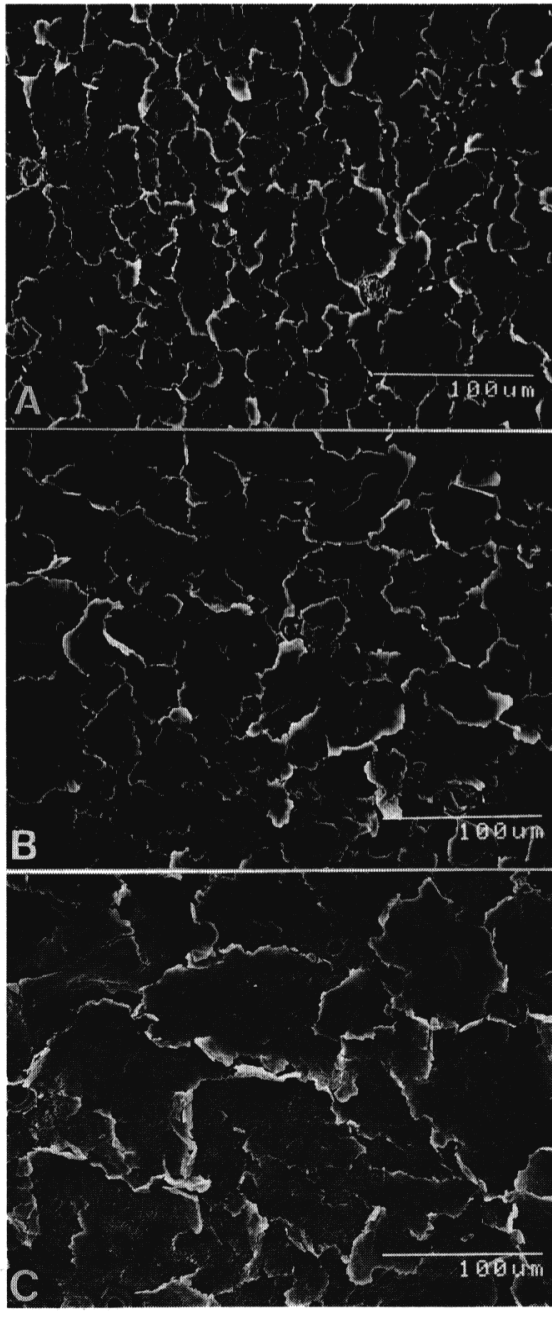

Albrigo, L.G. 1972b. IJltrastructure of cuticular surfaces and stomata of developing leaves and fruit of the 'Valencia' orange. J. Amer. Soc. Hort. Sci. 97:761-765.

Albrigo, L.G. 1972c. Variation in surface wax on oranges from selected groves in relation to fruit moisture loss. Proc. Florida State Hort. Soc. 85:262-263.

Bain, J.M. and D.M. McBean. 1967. The structure of the cuticular wax of prune plums and its influence as a water barrier. Austral. J. Biol. Sci. 20:895-900.

Baker, E.A. and J. Procopiou. 1975. The cuticles of Citrus species. Composition of the intracuticular lipids of leaves and fruits. J. Sci. Food Agr. 26:1347-1352.

Baker, E.A., J. Procopiou, and G.M. Hunt. 1975. The cuticles of Citrus species. Composition of leaf and fruit waxes. J. Sci. Food Agr. 26: 10931101

El-Otmani, M. and C.W. Coggins, Jr. 1985. Fruit development and growth regulator effects on normal alkanes of 'Washington' navel orange fruit epicuticular wax. J. Agr. Food Chem. 33:565-663.

El-Otmani, M., M.L. Arpaia, and C.W. Coggins, Jr. 1987. Developmental and topophysical effects on the $n$-alkanes of Valencia orange fruit epicuticular wax. J. Agr. Food Chem. 35:42-46.

El-Otmani, M., M.L. Arpaia,C.W. Coggins, Jr., J.E. Pehrson, Jr., and N.V. O’Connell. 1989. Developmental changes in 'Valencia' orange fruit epicuticular wax in relation to fruit position on the tree. Scientia Hort. 41:69-81.

Freeman, B., L.G. Albrigo, and R.H. Biggs. 1979. Ultrastructure and chemistry of cuticular waxes of developing Citrus leaves and fruits. J. Amer. Sot. Hort. Sci. 104:801-808

Nordby, H.E. and R.E. McDonald. 1990. Squalene in grapefruit wax as a possible natural protectant against chilling injury. Lipids 25:807-810.

Nordby, H.E. and R.E. McDonald. 1991. Relationship of epicuticular wax composition of grapefruit to chilling injury. J. Agr. Food Chem. 39:957-962.

Fig. 1. Epicuticular wax deposits on the surface of (A) interior canopy, (B) exterior canopy shaded, and (C) sun-exposed 'Marsh' grapefruit.

vious data (Nordby and McDonald, 1990, 1991) suggest that composition and morphology of grapefruit epicuticular wax influence CI development, possibly by restricting gas exchange. However, differences in epicuticular wax and grapefruit CI susceptibility could be related to senescence, but not necessarily to each other. Although these data are related to external CI symptom development, additional work is needed to determine the underlying cause of CI.

\section{Literature Cited}

Albrigo, L.G. 1972a. Distribution of stomata and epicuticular wax on oranges as related to stem end rind breakdown and water loss. J. Amer. Soc. Hort. Sci. 97:220-223.
Possingham, J.V., T.C. Chambers, F. Radler, and M. Grncarevic. 1967. Cuticular transpiration and wax structure and composition of leaves and fruit of Vitis vinifera. Austral. J. Biol. Sci. 20:1149-1153.

Purvis, A.C. 1980. Influence of canopy depth on susceptibility of 'Marsh' grapefruit to chilling injury. HortScience 15:731-733.

Purvis, A.C. 1984. Importance of water loss in the chilling injury of grapefruit stored at low temperature. Scientia Hort. 23:261-267.

SAS Institute. 1988. SAS/STAT user's guide. release 6.03. SAS Institute, Cary, NC.

Syvertsen, J.P. and L.G. Albrigo. 1980. Some effects of grapefruit tree canopy position on microclimate, water relations, fruit yield, and juice quality. J. Amer. Soc. Hort. Sci. 105:454-459.

Wang, C.Y. 1990. Alleviation of chilling injury of horticultural crops, p. 281-302. In: C.Y. Wang (ed.). Chilling injury of horticultural crops. CRC Press, Boca Raton, Fla. 